Original Research Paper

\title{
Optimization Design of Sea Cucumber Cleaning Parameters by Water Jet
}

\author{
${ }^{1,2}$ Xu Zhang, ${ }^{1}$ Changyuan Zhang, ${ }^{1}$ Fei Gao, ${ }^{1}$ Weiwei Xia, ${ }^{1}$ Peng Zhang and ${ }^{3}$ Zixiang Xu \\ ${ }^{1}$ Dalian Polytechnic University, Dalian, 116034, China \\ ${ }^{2}$ National Engineering Research Center of Seafood, Dalian Polytechnic University, Dalian 116034, China \\ ${ }^{3}$ Rizhao Xinbo Machinery Equipment Co., Ltd., Rizhao, 276824, China
}

Article history

Received: 25-12-2020

Revised: 10-03-2021

Accepted: 12-03-2021

Corresponding Author:

Xu Zhang

Dalian Polytechnic University,

Dalian, 116034, China

Email: zhangxu_dlut@163.com

\begin{abstract}
Aiming at the problem that the cleaning effect and surface integrity of the mechanical cleaning process cannot be solved simultaneously in the pretreatment of sea cucumber and according to the requirements of high efficiency, high quality and economy of sea cucumber body surface cleaning, a continuous directional cleaning device for sea cucumber abdomen and back based on the principle of water jet is designed. Through single factor experiment, the influence trend of jet parameters such as jet pressure, target distance and incidence angle on cleaning effect was analyzed. The cleaning parameters of sea cucumber are optimized by $\mathrm{L}_{9}\left(3^{4}\right)$ orthogonal design. The experimental results show that the cleaning effect of sea cucumber is closely related to the impact of water jet. Enhancing the impact of water jet will not only help improve the cleanliness of sea cucumber, but also increase the risk of skin damage of sea cucumber. The influence order of water jet parameters on the cleaning effect of sea cucumber is as follows: Jet pressure $>$ jet target distance $>$ jet incidence angle. When the jet pressure is $3.0 \mathrm{MPa}$, the jet target distance is 200 $\mathrm{mm}$ and the jet incidence angle is $70^{\circ}$, the cleanliness and integrity scores are 8.0 and 8.2 respectively and the comprehensive cleaning effect of this scheme is optimal. This study provides the basis for the research and development of sea cucumber water jet cleaning device and process optimization.
\end{abstract}

Keywords: Water Jet, Cleaning Device, Parameter Optimization, Sea Cucumber

\section{Introduction}

Sea cucumber is rich in a variety of trace elements, mucopolysaccharide and cholesterol free, high protein. It is not only delicious, but also has high nutritional value (Ru et al., 2019) and medicinal value (Fan, 2001; Chunyun et al., 2004). In recent years, the output of sea cucumber in China has increased year by year and the demand for rapid and large-scale mechanized processing technology and equipment is increasingly significant. In this context, many scholars have studied the effects of different processes and parameters (Sun et al., 2017; Liu et al., 2015) on the nutritional quality (Li et al., 2019b; 2018; Meng et al., 2017), texture-characteristics (Xiong et al., 2020; Xin et al., 2019) and edibility (Liu et al., 2018; Shaoxiao et al., 2017) under the condition of mechanical processing. However, there is no report on the effect of processing technology on the appearance quality of sea cucumber. Body surface cleaning process is one of the important processing procedures to ensure the appearance quality of sea cucumber (Xu et al., 2009). Traditional sea cucumber cleaning is manual, with low cleaning efficiency and poor-quality stability, which cannot meet the needs of large-scale sea cucumber processing. Sea cucumber cleaning and processing mechanization, automation has become an inevitable trend. At present, the cleaning and processing technologies widely used by seafood processing enterprises mainly include washing, immersion, brushing, chemical cleaning, bubble and ultrasonic (Xu et al., 2011; Yan et al., 2019). Although the above methods can realize batch 
cleaning of sea cucumber, there are still some deficiencies in cleaning effect. The specific performance is as follows: (1) It is difficult to remove the strong adhesion impurities and rotten tissue on the sea cucumber surface by washing and soaking. Although the cleaning effect can be improved by other cleaning methods, manual secondary sorting is still needed. (2) Brushing method can obtain high surface cleanliness of sea cucumber, but it is easy to cause damage, especially the damage to the stomach and foot of sea cucumber, which affects the appearance quality of sea cucumber products. Therefore, the research of efficient and low loss sea cucumber cleaning technology and equipment is one of the key points in the field of sea cucumber processing.

Water jet cleaning technology is one of the physical cleaning technologies to remove the surface attachments of processed objects/parts in the fields of engineering, agriculture, etc., with the characterristics of rapid and continuous large-scale operation (Fuchs et al., 2019; Liu et al., 2016; Xia et al., 2020). In the processing of aquatic food, fish descaling, shellfish cleaning and impurity removal based on water jet have been gradually studied and applied ( $\mathrm{Li}$ et al., $2019 \mathrm{a} ; 2020)$. Due to the directionality of water jet, the directional cleaning of sea cucumber surface can be realized by using this feature, so as to solve the shortcomings of existing methods. It is worth further exploring to construct a new technology and device for sea cucumber cleaning based on the principle of water jet.

Therefore, based on the principle of water jet, a sea cucumber directional cleaning device is designed in this study. The influence trend of water jet parameters on the cleaning effect of sea cucumber is studied through experiments and the optimization method of water jet cleaning process parameters based on sensory evaluation of sea cucumber cleaning effect is proposed. It provides the basis for the research and development of sea cucumber water jet cleaning device and process optimization.

\section{Design of Water Jet Cleaning Device for Sea Cucumber}

\section{Principle of Water Jet Cleaning}

The principle of directional cleaning of sea cucumber with water jet is shown in Fig. 1. The sea cucumber is fixed on the transmission device and transported to the cleaning station at a certain speed $\mathrm{V}$. The nozzle in front of the sea cucumber jets pressure water. Under the impact of water jet, the attachments and epidermis on the back and on both sides of the sea cucumber are cleaned away. Because the gastropod part is not impacted by the water jet, the surface of sea cucumber can be cleaned in a directional way. In this process, when the water jet parameters (jet pressure $P$, jet distance $L$ and jet angle $\alpha$ ) change, sea cucumber will be subject to different jet impact force. The cleaning effect of sea cucumber is affected.

\section{Overall Design Scheme and Working Principle}

The sea cucumber water jet cleaning device is mainly composed of mechanical body, cleaning device, conveying device, discharging device and protection device. The structure is shown in Fig. 2.

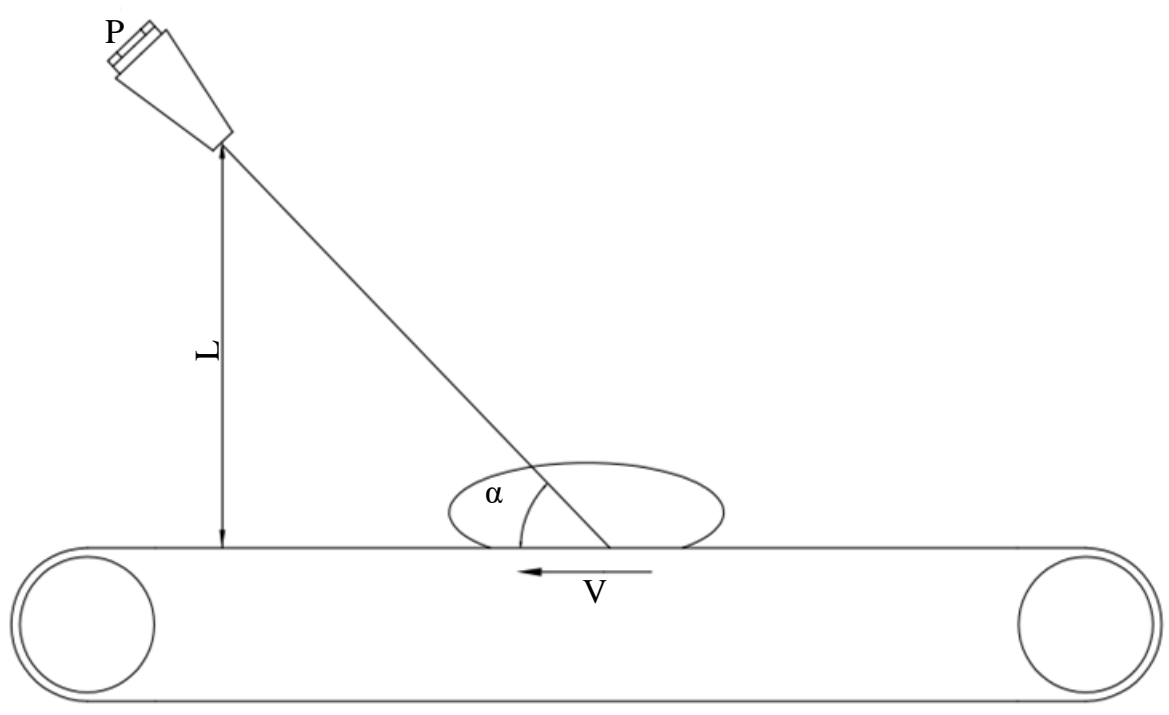

Fig. 1: Schematic diagram of water jet sea cucumber cleaning 


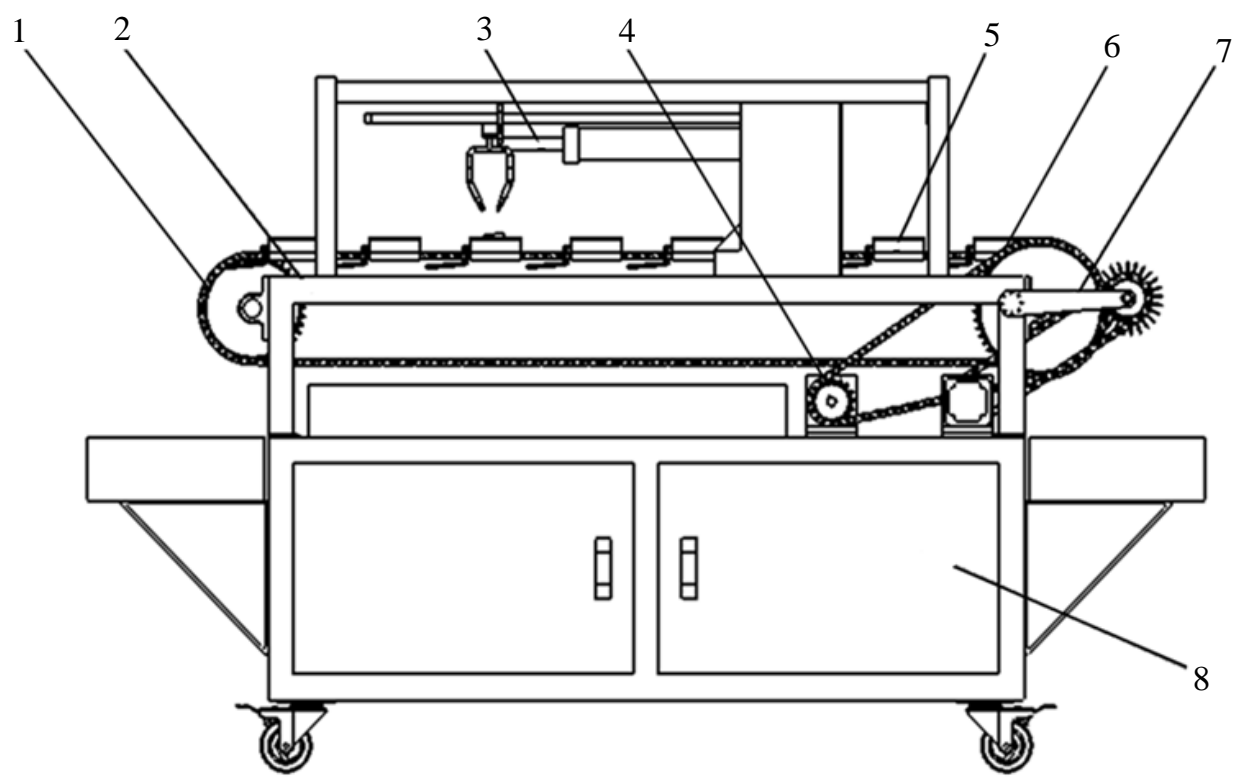

Fig. 2: Structure diagram of sea cucumber cleaning device by water jet. Driven sprocket 2. Frame 3. Nozzle group 4. Driving device 5. Clamping device 6. Driving sprocket 7. Discharging device 8. Water circulation

\section{Experimental Method of Sea Cucumber Cleaning by Water Jet}

\section{Materials}

The sea cucumber samples used in the experiment are the salted sea cucumber raw materials provided by Dalian sea cucumber processing enterprises in Liaoning Province. The raw materials with the same weight and specifications in the same batch were randomly selected. The single head weight is $(25 \pm 5)$ $\mathrm{g}$, the density is $(1.15 \pm 0.02) \mathrm{g} / \mathrm{m}^{3}$ and the hardness is $(10.63 \pm 1.78) \mathrm{N}$.

\section{Instruments and Equipment}

The equipment prototype used in the test is shown in Fig. 3.

\section{Test Method}

\section{Experiment Process}

After the test prototype of the water jet sea cucumber cleaning device runs smoothly, the jet pressure, jet target distance and jet incidence angle are set and then the sea cucumber is placed in the clamping device evenly distributed on the chain conveyor according to the head forward and the tail backward. The stepping motor is adjusted to make the sea cucumber materials transported to the cleaning station to complete the water jet cleaning operation.
Finally, the cleanliness and integrity of sea cucumber of sea cucumber is evaluated refer sensory evaluation to tables. The experiment process of this study is shown in Fig. 4.

\section{Single Factor Test}

In this test, the fan-shaped nozzle is selected. The nozzle parameters are $60^{\circ}$ of cone angle, $4 \mathrm{~mm}$ of outlet length and $1 \mathrm{~mm}$ of outlet diameter. The fixed feed speed is $25 \mathrm{~mm} / \mathrm{s}$ and jet pressure, jet target distance and jet incidence angle are used to conduct single factor experiments on sea cucumber. After the preliminary experiment, the value range of these three control parameters was determined: Jet pressure (1.0-5.0 MPa), jet target distance $(160-240 \mathrm{~mm})$ and jet incidence angle $\left(50-90^{\circ}\right)$. The test scheme is shown in Table. 1 .

\section{Orthogonal Test}

Jet pressure, jet target distance and jet incidence angle are selected as the experimental factors for $\mathrm{L}_{9}\left(3^{4}\right)$ orthogonal test.

\section{Index and Detection Method}

Sensory evaluation method is used to evaluate the surface cleanliness and surface integrity of sea cucumber after cleaning. 10 professionals are invited to evaluate the sea cucumber after the water jet cleaning and take its average score. The sensory evaluation criteria for the surface cleanliness and surface integrity of sea cucumber after cleaning are shown in Tables 2 and 3. 


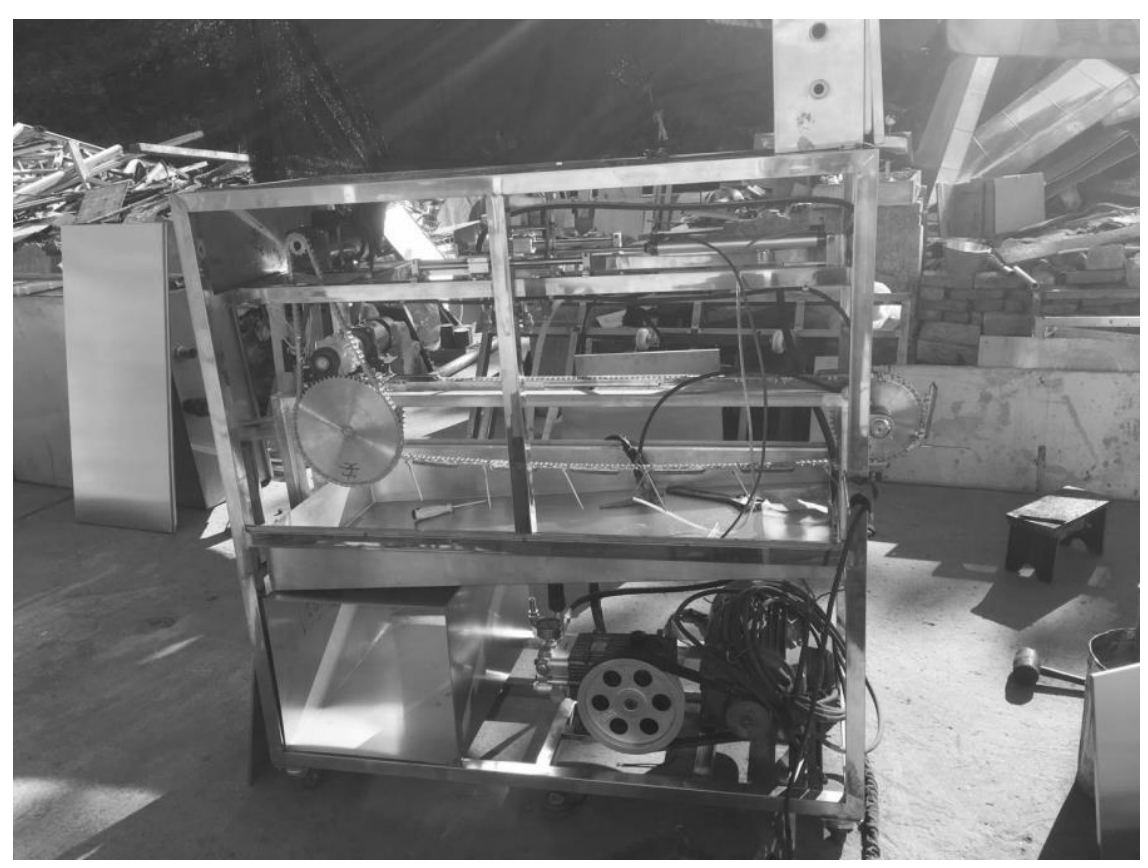

Fig. 3: The experimental prototype of sea cucumber water jet cleaning device

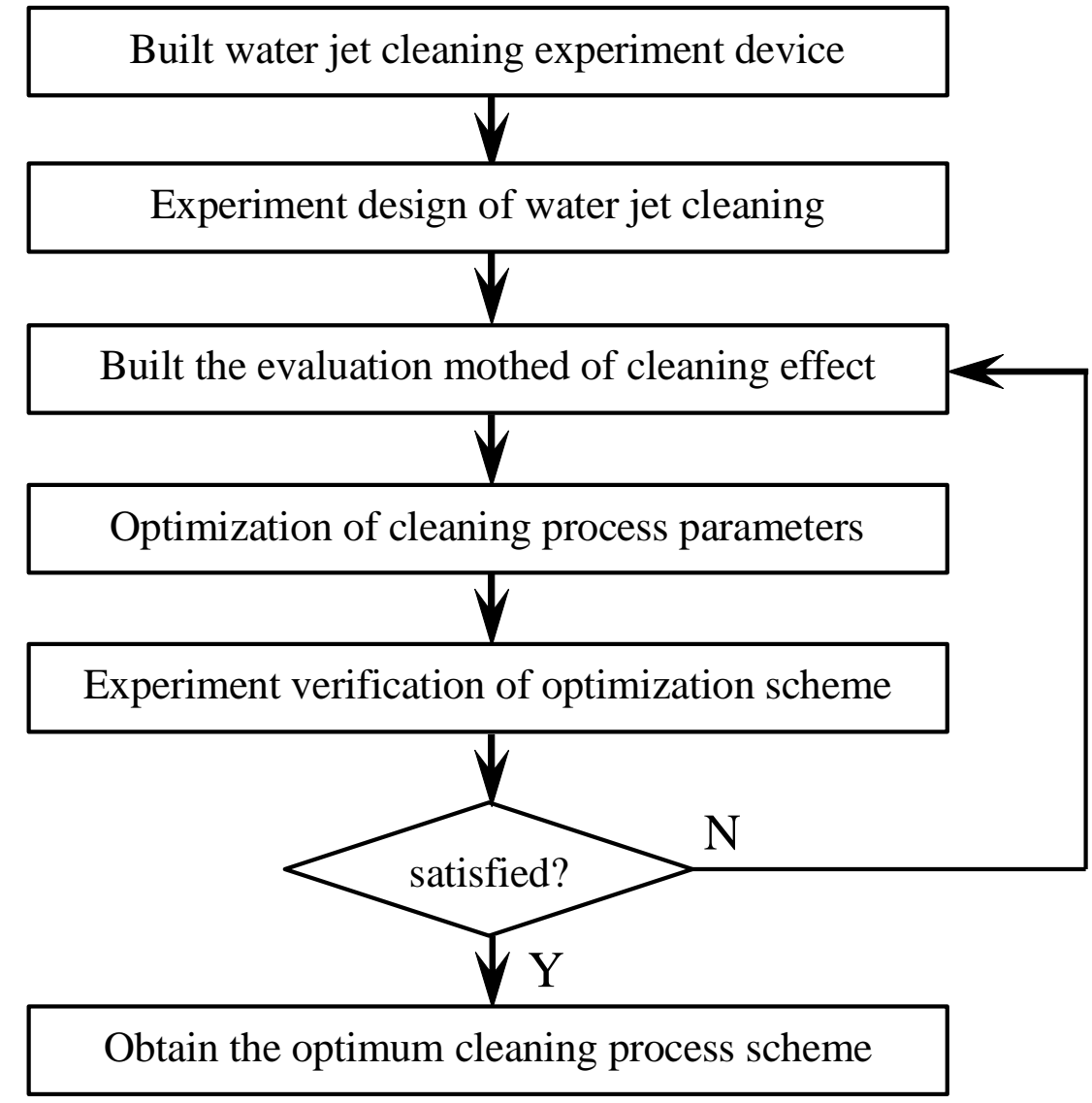

Fig. 4: The experiment process 
Table 1: Single factor test scheme

\begin{tabular}{|c|c|c|c|c|}
\hline Grouping & No. & Fixed condition & & Test condition \\
\hline \multirow[t]{5}{*}{ Group 1} & 1 & Jet incidence angle: $70^{\circ}$ & Jet pressure $(\mathrm{MPa})$ & 1.0 \\
\hline & 2 & Jet target distance: $200 \mathrm{~mm}$ & & 2.0 \\
\hline & 3 & & & 3.0 \\
\hline & 4 & & & 4.0 \\
\hline & 5 & & & 5.0 \\
\hline \multirow[t]{5}{*}{ Group 2} & 6 & Jet pressure: $3.0 \mathrm{MPa}$ & Jet target distance $(\mathrm{mm})$ & 160.0 \\
\hline & 7 & Jet incidence angle: $70^{\circ}$ & & 180.0 \\
\hline & 8 & & & 200.0 \\
\hline & 9 & & & 220.0 \\
\hline & 10 & & & 240.0 \\
\hline \multirow{5}{*}{ Group 3} & 11 & Jet pressure: $3.0 \mathrm{MPa}$ & Jet incidence angle $\left(^{\circ}\right)$ & 50.0 \\
\hline & 12 & Jet target distance: $200 \mathrm{~mm}$ & & 60.0 \\
\hline & 13 & & & 70.0 \\
\hline & 14 & & & 80.0 \\
\hline & 15 & & & 90.0 \\
\hline
\end{tabular}

Table 2: Sensory evaluation criteria for surface cleanliness of sea cucumber

Score Qualitative description

8-10 There is no stain on the surface of sea cucumber and the epidermis was removed evenly.

6-8 There are a few stains on the surface of sea cucumber or a small amount of skin on both sides of sea cucumber are not removed

4-6 There were obvious stains on the surface of sea cucumber or large area of epidermis on both sides of sea cucumber were not removed.

2-4 A large area of stains on the surface of sea cucumber is not removed and the epidermis on both sides of sea cucumber is not removed.

1-2 The stains on the surface of sea cucumber were not removed.

Table 3: Sensory evaluation criteria for surface integrity of sea cucumber

\begin{tabular}{ll}
\hline Score & Qualitative description \\
\hline $8-10$ & No damage is found on the surface of sea cucumber. \\
$6-8$ & There are a few honeycomb spots on the surface of sea cucumber. \\
$4-6$ & There is a large area of honeycomb or a small number of shallow cracks on the surface of sea cucumber. \\
$2-4$ & The skin of sea cucumbers is detached in large area or there are obvious cracks on the surface of sea cucumbers. \\
$1-2$ & The surface of sea cucumber is deeply damaged and the internal tissue is clearly visible. \\
\hline
\end{tabular}

\section{Test Results and Analysis}

\section{Single Factor Test}

It can be seen from Fig. 5 that the score of sea cucumber surface cleanliness increases with the increase of jet pressure, while the score of sea cucumber surface integrity decreases with the increase of jet pressure. With the increase of jet pressure, the impact force of jet also increases and the stains on the sea cucumber surface fall off under the shear force of the water jet. However, when the water jet shear stress exceeds the shear failure strength of the sea cucumber surface, the sea cucumber surface will receive shear failure and form honeycomb damage points. When the shear force is further increased, cracks in the top-down direction will appear on both sides of the sea cucumber.

It can be seen from Fig. 6 that with the increase of jet target distance, the impact force of jet will decrease and the score of surface cleanliness of sea cucumber will decrease, while the impact force of jet will decrease. Meanwhile, the damage of sea cucumber surface is also reduced and the score of sea cucumber surface integrity will increase.

According to Fig. 5 and 6, the cleaning effect is related to the intensity of jet impact force, which is determined by the jet pressure and jet target distance, but there are some differences in their modes of action. The change of jet target distance not only affects jet impact intensity, but also changes the uniformity of jet impact. The farther the distance between jet target is, the better the uniformity of jet is. In order to improve the surface integrity score, the strategy of increasing jet target distance should be given priority compared with the strategy of reducing jet pressure.

According to Fig. 7, with the increase of jet incidence angle, the vertical component of jet impact force becomes large, while the horizontal component becomes small. The surface cleanliness score of sea cucumber is mainly related to the vertical component of jet impact force. The surface cleanliness score of sea cucumber increases linearly with the increase of jet incidence angle. In terms of surface damage, excessive vertical component of jet impact force will lead to honeycomb or cracks on the back surface of sea cucumber. However, if the horizontal component of the jet impact force is too large, the skin of the front-end of the sea cucumber will be torn. Therefore, the surface damage of the sea cucumber will be caused by too large or too small incident angle of the jet. When the jet incidence angle is $70^{\circ}$, the sea cucumber surface integrity score reaches the peak. 


\section{Orthogonal Test}

The $\mathrm{L}_{9}\left(3^{4}\right)$ orthogonal test is designed with the jet pressure, jet target distance and jet incidence angle as the factors and the cleanliness score and integrity score of sea cucumber surface as the index. The factor level table is shown in Table 4.

It can be seen from Table 5 that the order of influence of each factor on cleanliness score is: Jet pressure > jet target distance > jet incidence angle.
The parameter combination of the optimal cleaning score is $\mathrm{A}_{3} \mathrm{~B} 1 \mathrm{C}_{2}$, that is, the jet pressure is $4.0 \mathrm{MPa}$, the jet target distance is $180 \mathrm{~mm}$ and the jet incidence angle is $70^{\circ}$. The order of influencing factors on the integrity score is: Jet pressure > jet target distance > jet incidence angle. The parameter combination of the optimal integrity score is $\mathrm{A}_{1} \mathrm{~B}_{3} \mathrm{C}_{1}$, that is, the jet pressure is $2.0 \mathrm{MPa}$, the jet target distance is $220 \mathrm{~mm}$ and the jet incidence angle is $60^{\circ}$.

Table 4: Factor level

\begin{tabular}{llll}
\hline Level & A Jet pressure $(\mathrm{MPa})$ & B Jet target distance $(\mathrm{mm})$ & C Jet incidence angle $\left(^{\circ}\right)$ \\
\hline 1 & 2.0 & 180 & 60 \\
2 & 3.0 & 200 & 70 \\
3 & 4.0 & 220 & 80 \\
\hline
\end{tabular}

Table 5: Orthogonal test scheme and results

\begin{tabular}{|c|c|c|c|c|c|}
\hline No. & $\mathrm{A}$ & $\mathrm{B}$ & $\mathrm{C}$ & Cleanliness score & Integrity score \\
\hline$\overline{1}$ & 1 & 1.00 & 1.00 & 7.50 & 8.2 \\
\hline 2 & 1 & 2.00 & 2.00 & 6.80 & 8.9 \\
\hline 3 & 1 & 3.00 & 3.00 & 6.00 & 9.4 \\
\hline 4 & 2 & 1.00 & 2.00 & 8.90 & 6.8 \\
\hline 5 & 2 & 2.00 & 3.00 & 7.80 & 7.5 \\
\hline 6 & 2 & 3.00 & 1.00 & 6.90 & 8.9 \\
\hline 7 & 3 & 1.00 & 3.00 & 9.80 & 5.0 \\
\hline 8 & 3 & 2.00 & 1.00 & 9.00 & 6.8 \\
\hline 9 & 3 & 3.00 & 2.00 & 8.20 & 7.3 \\
\hline \multirow[t]{4}{*}{ Cleanliness } & $\mathrm{K}_{1}$ & 6.77 & 8.73 & 7.80 & \\
\hline & $\mathrm{K}_{2}$ & 7.87 & 7.87 & 7.97 & \\
\hline & $\mathrm{K}_{3}$ & 9.00 & 7.03 & 7.87 & \\
\hline & $\mathrm{R}$ & 2.23 & 1.07 & 0.17 & \\
\hline \multirow[t]{4}{*}{ Integrity } & $\mathrm{K}_{1}$ & 8.83 & 6.67 & 7.97 & \\
\hline & $\mathrm{K}_{2}$ & 7.73 & 7.73 & 7.67 & \\
\hline & $\mathrm{K}_{3}$ & 6.37 & 8.53 & 7.30 & \\
\hline & $\mathrm{R}$ & 2.46 & 1.86 & 0.67 & \\
\hline
\end{tabular}

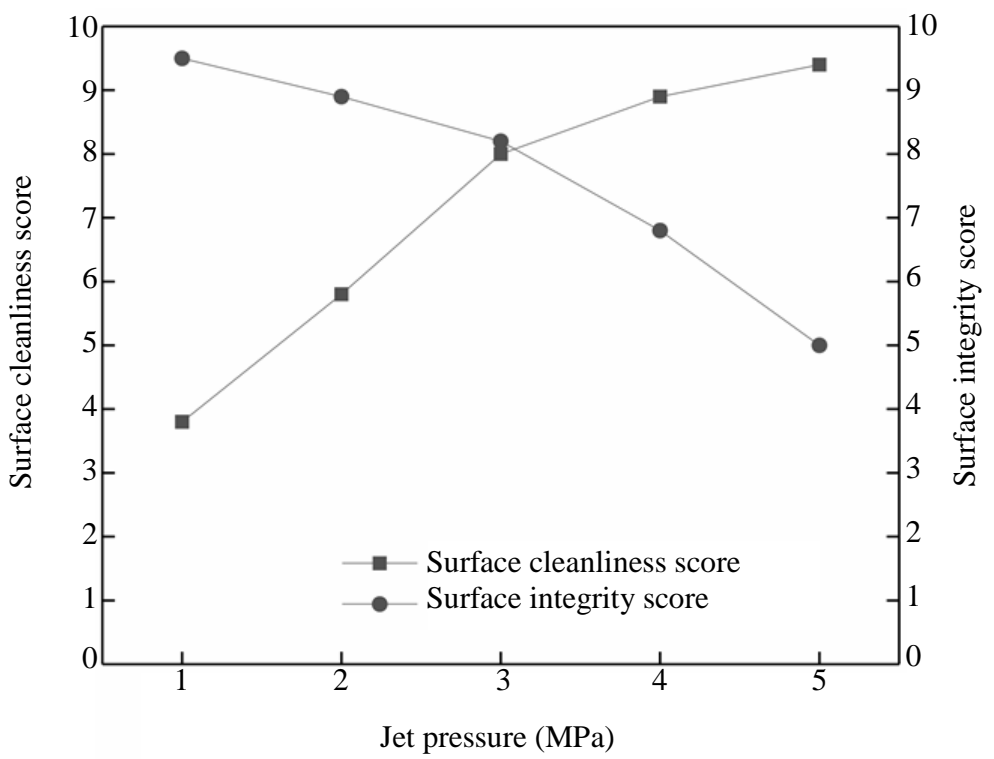

Fig. 5: The effect of jet pressure on the cleaning effect of sea cucumbers 


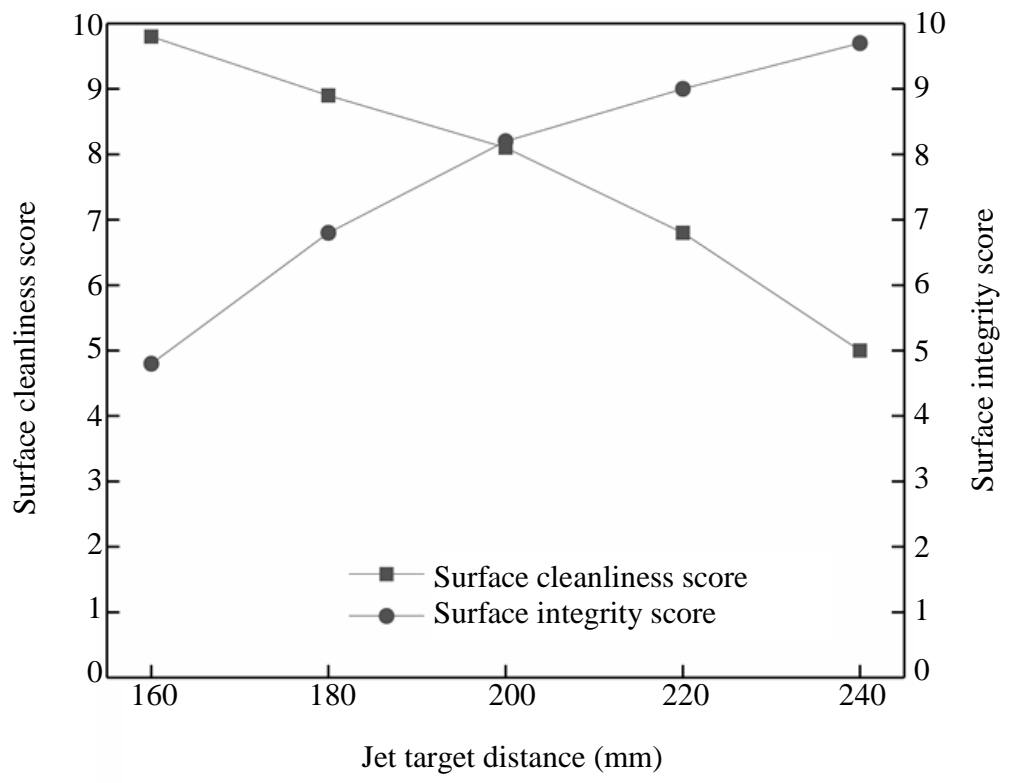

Fig. 6: The effect of jet target distance on sea cucumber cleaning effect

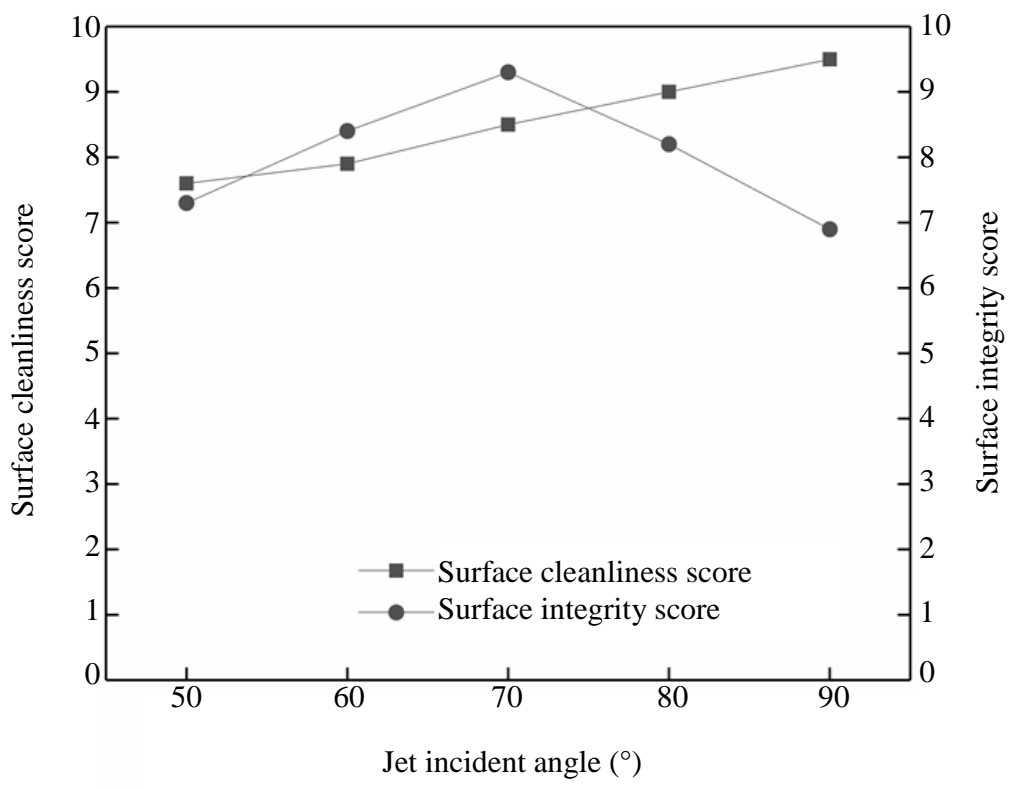

Fig. 7: The effect of jet incident angle on the cleaning effect of sea cucumber

The experimental results show that when the parameter combination of $\mathrm{A}_{3} \mathrm{~B}_{1} \mathrm{C}_{2}$ is used for sea cucumber water jet cleaning, the sea cucumber surface cleanliness score reaches 9.7. The sea cucumber surface has no stain and the cleaning uniformity is good. However, the surface integrity of sea cucumber is only 5.2 and honeycomb and cracks are obvious on the surface of sea cucumber. The qualified rate of processed products was too low. When the parameter combination of $\mathrm{A}_{1} \mathrm{~B}_{3} \mathrm{C}_{1}$ is used, the sea cucumber surface integrity score reaches 9.5. The sea cucumber skin is not damaged and the sea cucumber surface cleanliness score is only 6.0. Moreover, there are obvious stains and unshelled areas on both sides of the sea cucumber surface. In actual production, the sea cucumber with this cleaning effect cannot meet the requirements of the apparent quality of sea cucumber and manual secondary cleaning is needed, which increases the cost of cleaning. According to the characteristics of water jet cleaning, a compromise should be made between the cleaning degree and damage degree of sea cucumber surface when the technological standard of sea cucumber cleaning is established. 


\section{Optimization of Process Parameters}

According to the characteristics of water jet cleaning, it is necessary to compromise between the surface cleanliness degree and the surface integrity degree when building the cleaning technology standard. Using the response surface method, multiple quadratic equation regression analysis is conducted to establish the functional relationship between the surface cleanliness degree $Y_{1}$ and the surface integrity degree $Y_{2}$ :

$$
\begin{aligned}
& Y_{1}=8.2+1.18 x_{1}-0.41 x_{2}+0.46 x_{3}-1.08 x_{1} x_{2} \\
& +0.075 x_{1} x_{3}-0.075 x_{1}^{2}-0.05 x_{2}^{2}-1.05 x_{3}^{2} \\
& Y_{2}=6.52-1.14 x_{1}+0.46 x_{2}-0.42 x_{3}+1.12 x_{1} x_{2} \\
& -0.15 x_{1} x_{3}-0.05 x_{2} x_{3}+0.18 x_{1}^{2}+0.28 x_{2}^{2}+0.85 x_{3}^{2}
\end{aligned}
$$

Normalize Equations (1) and (2) and set the weight coefficients of $Y_{1}$ and $Y_{2}$ as 0.6 and 0.4 , respectively. Finally, the comprehensive optimization equation is obtained:

$$
\begin{aligned}
& Y=7.528+0.252 x_{1}-0.062 x_{2}+0.108 x_{3}-0.2 x_{1} x_{2}- \\
& 0.015 x_{1} x_{3}-0.02 x_{2} x_{3}+0.027 x_{1}^{2}+0.082 x_{2}^{2}-0.29 x_{3}^{2}
\end{aligned}
$$

According to the comprehensive optimization equation, the optimal cleaning process parameters were obtained as follows: Jet pressure $3 \mathrm{MPa}$, jet target distance $200 \mathrm{~mm}$, jet incidence angle $70^{\circ}$ and the score of surface cleanliness and integrity of sea cucumber are 8.0 and 8.2 , respectively. Under the above technological parameters, three confirmatory experiments are carried out and the test results of the score of surface cleanliness and integrity of sea cucumber are 8.1 and 8.1, respectively. The effectiveness of the optimization scheme was verified.

\section{Conclusion}

(1) According to the principle of water jet cleaning, the design scheme of sea cucumber cleaning device with the multi-functions of conveying, cleaning, protection and unloading is put forward, which realizes the continuous directional cleaning of the front and back of sea cucumber.

(2) Based on the experimental prototype, the cleaning experiment of sea cucumber was carried out and the experiment results was showed that the increase of jet pressure and the decrease of jet target distance can improve the cleaning degree of sea cucumber, but also increase the possibility of sea cucumber damage. The larger the jet incidence angle is, the higher the cleaning degree of sea cucumber is and the larger and smaller jet incidence angle will increase the risk of sea cucumber damage. Through range analysis, the primary and secondary factors affecting the score of cleanliness and integrity are jet pressure, jet target distance and jet incidence angle.

(3) The parameters of sea cucumber water jet cleaning were optimized. When the jet pressure is $3.0 \mathrm{MPa}$, the jet target distance is $200 \mathrm{~mm}$ and the jet incidence angle is $70^{\circ}$, the cleanliness and integrity scores are 8.0 and 8.2 respectively. The comprehensive cleaning effect of this scheme is optimal.

(4) On the basis of the method in this study, the structure design and automatic control method of sea cucumber body surface cleaning device can be further studied. At the same time, the method in this study can provide a research basis for the development of mechanized and automatic cleaning equipment for typical seafood (fish, shellfish, sea cucumber, etc.).

\section{Acknowledgement}

This work is grateful to the financial supports from National Key R\&D Program of China (No. 2018YFD0400800). Liaoning Natural Science Foundation (No. 2019ZD0123).

\section{Author Contributions}

Xu Zhang and Changyuan Zhang: Designed and performed the experiments, analyzed the data and prepared the paper.

Fei Gao and Weiwei Xia: Collection and/or assembly of data.

Peng Zhang and Zixiang Xu: Participated to collect the materials related to the experiment and revised the manuscript.

\section{Ethics}

The authors declare their responsibility for any ethical issues that may arise after the publication of this manuscript.

\section{References}

Chunyun, Z., Yingeng, W., Xiaojun, R., Huiling, S., \& Shugang, D. (2004). Natrual resouces, culture and problems of sea cucumber worldwide. Marine Fisheries Research, 25(3), 89-97. http://dx.doi.org/10.3969/j.issn.1002-3461.2001.04.010

Fan, H. (2001). Sea cucumber: research and development on the health care functioning of sea cucumber and its ingredients. Chin Mar Med, 4, 37-42. http://dx.doi.org/10.3969/j.issn.1002-3461.2001.04.010

Fuchs, E., Kricke, S., Schöhl, E., \& Majschak, J. P. (2019). Effect of industrial scale stand-off distance on water jet break-up, cleaning and forces imposed on soil layers. Food and Bioproducts Processing, 113, 129-141. https://doi.org/10.1016/j.fbp.2018.11.008 
Li, C., Li, H., Guo, S., Li, X., \& Zhu, X. (2018). Evaluation of processing methods on the nutritional quality of sea cucumber (Apostichopus japonicus Selenka). Journal of Aquatic Food Product Technology, 27(4), 406-417. http://dx.doi.org/10.1080/10498850.2013.803271

Li, R., Li, X., Zhang, X., Yang, J., Lu, J., Wang, H., \& Cheng, S. (2019a). Design of Experimental Equipment for Water Jet Cleaning of Aquatic Raw Materials. https://doi.org/10.12677/met.2019.85042.

Li, M., Qi, Y., Mu, L., Li, Z., Zhao, Q., Sun, J., \& Jiang, Q. (2019b). Effects of processing method on chemical compositions and nutritional quality of ready-to-eat sea cucumber (Apostichopus japonicus). Food Science \& Nutrition, 7(2), 755763. http://dx.doi.org/10.1002/fsn3.921

Li, R., Meng, X., Zhong, S., Lu, J., Zhang, X., Tao X. (2020). Experimental study on descaling technology of typical freshwater fish based on water jet. Food \& Machinery, vol. 331, no. 3, pp. 101-104. http://dx.doi.org/10.13652/j.issn.10035788.2020.03.019.

Liu, C., Wu, L., Xue, Y., Liu, F., Sun, S., \& Wang, L. (2018). Effect of cooking methods on bioaccessibility of $\mathrm{Zn}, \mathrm{Se}, \mathrm{Cd}, \mathrm{Cu}$ in sea cucumber (Apostichopus japonicus). Food science and biotechnology, 27(3), 899-904. http://dx.doi.org/10.1007/s10068-017-0298-5.

Liu, H. F., Zhang, H. S., \& Yuan, Y. (2016). Research on the Nozzle of the Licorice Cleaning Equipment Based on FLUENT. Hydraulics Pneumatics \& Seals, 09. https://doi:10.3969/j.issn.1008-0813.2016.09.006

Liu, Q., Cao, R., Guo, Y. Y., LI, Z. C., \& ZHAO, L. (2015). Effects of sea cucumber processing on the quality of its products. Modern Food Science \& Technology, vol. 31, no. 12, pp 313-317. http://dx.doi.org/10.13982/j.mfst.16739078.2015.12.047.

Meng, S., Zhang, H., Sun, J., \& Liu, Q. (2017). Study on nutritional value of instant sea cucumber processed by the new processing approach. American Journal of Biochemistry and Biotechnology, vol. 13, no 1, pp 5157. http://dx.doi.org/10.3844/ajbbsp.2017.51.57.

Ru, X., Zhang, L., Li, X., Liu, S., \& Yang, H. (2019). Development strategies for the sea cucumber industry in China. Journal of Oceanology and Limnology, 37(1), 300-312. https://doi.org/10.1007/s00343-019-7344-5
Shaoxiao, Z., Mingjing, Z., Ling, C., Zebin, G., \& Baodong, Z. (2017). Inactivation kinetics model of sea cucumber processed by high hydrostatic pressure and the storage quality of soft canned sea cucumber. Journal of Chinese Institute of Food Science and Technology, 11 . http://dx.doi.org/10.16429/j.1009-7848.2017.11.023

Sun, J., Yang, T., Liu, Q., \& Sun, Z. (2017). Optimization of key technology for instant sea cucumber processing through fuzzy evaluation and response surface methodology. American Journal of Biochemistry and Biotechnology, vol. 13, no. 2, pp 99-110. http://dx.doi.org/10.3844/ajbbsp.2017.99.110.

Xia, W., Ma, J., Zhang, X., Wen, B., Lu, J., \& Wang, H. (2020). Simulation analysis of fish descaling based on fluent water jet. Modeling and Simulation, vol. 9, no. 4, pp. 419-429. https://doi.org/10.12677/MOS.2020.94041

Xin, G., Zhao, H., Zhang, L. F., \& Liu, Q. 2019. Rheological changes of sea cucumber stichipus japonicus during different heated times. African Journal of Food Science Research, vol. 7, no. 1, pp 1-5. http: //dx.doi.org/ 10.5897/IJFA11.003.

Xiong, X., He, B., Jiang, D., Dong, X., Yu, C., \& Qi, H. (2020). Postmortem biochemical and textural changes in the sea cucumber Stichopus japonicus body wall (SJBW) during iced storage. LWT, 118, 108705. http://dx.doi.org/10.1016/j.lwt.2019.108705

Xu, W. Q., Cai, S. J., \& Shen, J. (2011). Continuous cooking technology and equipment of fresh sea cucumber. Food Science and Technology, 1. http://dx.doi.org/10.13684/j.cnki.spkj.2011.01.046

Xu, W., Shen, J., Xue, C., Cai, S., \& Lin, W. (2009). Experimental study on cleaning technology of fresh sea cucumber. Fishery modernization, vol. 36, no. 6, pp. 42-45. http://dx.doi.org/10.3969/j.issn.10079580.2009.06.010

Yan, Y., He, S., \& Li, L. (2019). Research progress on processing technology of sea cucumber. Modern Food, no. 1, pp. 8-11. http://dx.doi.org/10.16736/j.cnki.cn41$1434 /$ ts.2019.01.003 